\title{
TOPIC INFLUENCES ON ELECTRONIC MEETING RELEVANT COMMENTS
}

\author{
Milam Aiken, University of Mississippi, aiken@bus.olemiss.edu \\ Linwu Gu, Indiana University of Pennsylvania, Linwu.Gu@iup.edu \\ Jianfeng Wang, Indiana University of Pennsylvania, jwang@iup.edu \\ Mahesh Vanjani, Texas Southern University, vanjanim@tsu.edu
}

\begin{abstract}
Only rarely have researchers attempted to mathematically model the complex interrelationships of variables within an electronic meeting. Here, we show how topic-related measures can be used by an artificial neural network to accurately forecast the number of relevant comments generated by each person in these automated meetings. In comparison, naïve and multilinear regression forecasts were significantly different from the actual numbers of comments.
\end{abstract}

Keywords: Electronic Meetings, Group Decision Support Systems (GDSS), Artificial Neural Networks

\section{INTRODUCTION}

Groups using electronic meeting systems (EMS) otherwise known as group support systems (GSS) or group decision support systems (GDSS) - have been studied for over 20 years [17], and most research has shown that electronic meetings are superior to traditional, oral meetings when the group size is greater than seven and all individuals need to contribute, as in a brainstorming session [21]. In a typical meeting using an EMS, group members exchange typed comments about a proposed topic anonymously in a face-to-face environment $[10,24]$. Because anonymity is provided, there is less evaluation apprehension (fear of others' criticism) in these meetings, and because all members can type and read comments simultaneously, there is more participation. Because there is less evaluation apprehension and more participation, groups using an EMS often generate more comments during the session and are more satisfied [13].

However, many interrelated variables can influence meeting satisfaction and the number of comments produced, including individual typing and reading speeds, the specific idea generation technique used, and the specific task or topic of the meeting $[12,22]$. The purpose of this paper is to investigate how the choice of meeting topic can affect the number of relevant comments produced by each member of the group.

\section{MODELLING ELECTRONIC MEETINGS}

Some attempts have been made to model the interrelationships among electronic meeting variables mathematically. For example, one study used a linear equation to show how the number of comments generated in an EMS meeting varies with group size [25], and another demonstrated through formulas the costs and benefits of electronic meetings [6]. A third study [7] provided mathematical models of idea processing and generating rates, optimum group sizes, and time savings.

But, few researchers have attempted to use these models to actually forecast meeting outcomes such as process satisfaction or the number of comments generated by the group [26]. Perhaps part of the reason is that most statistical techniques cannot adequately accommodate the complex, interrelated nature of the variables in the meeting. Artificial neural networks (ANNs), otherwise known as artificial neural systems (ANSs) or simply neural networks (NNs), can provide the solution to this forecasting problem, as they can model non-linear relationships among variables and are more accurate than competing statistical forecasting techniques such as Logit and Probit [14]. Yet, neural networks are still relatively rarely used in the realm of GSS research because of a lack of awareness of the technique, a lack of access to the software, or a lack of knowledge of how to use the programs.

A few studies have shown how neural networks can accurate forecast variables within electronic meetings, however. For example, a neural network classified participants as being within an electronic meeting or verbal meeting with $90 \%$ accuracy (versus 76\% accuracy using linear regression) based upon their responses on evaluation apprehension, satisfaction, and extent of participation [1]. In another study, a neural network predicted the length of the meetings based upon knowledge of the topic, complexity of the problem, and experience with the software with $76 \%$ accuracy [3].

Using a similar technique called logical abduction, one study [5] showed that researchers were able to forecast meeting process satisfaction using only group size and 
idea generation technique with a mean absolute percentage error (MAPE) of $8.77 \%$ versus an MAPE of $44.52 \%$ with a multi-linear regression model. Using comment generation rate, production blocking, and evaluation apprehension variables, researchers were able to predict meeting process satisfaction with an MAPE of only $6.54 \%$.

\section{TOPIC EFFECTS IN ELECTRONIC MEETINGS}

Many different topics have been used in prior studies of meetings, including:

- What are the advantages and disadvantages of having two thumbs on each hand? [2].

- "How high does the chance of later employment have to be before you would advise a fellow student to join a very desirable trainee program prior to finishing the undergraduate thesis?" [11].

- "How can we solve the parking problem on campus?" [19].

- "Should tuition be raised?" [2].

- "How could you safely change a tire on a busy expressway at night?" [16].

- " "How can the spread of AIDS be reduced?" [23].

- "What makes for success in our culture?" [

- "How can we encourage more tourists to visit the city?" [23].

- "What type of soft drink should be in the vending machines on campus?" [2].

With each of these topics, individual group members had varying degrees of knowledge about, interest in, and ability to influence the subject. But if a topic is boring, or the group members have little knowledge of the subject or control over the solution of the problem, they may be more likely to switch spontaneously to another topic to pass the time [9]. For example, if a group of undergraduate business students in an electronic meeting is asked to propose new procedures for brain surgery, they are not likely to type many relevant, on-topic comments, but instead, might start to exchange comments about sports, politics, or something else more interesting to them.

In most brainstorming meetings, the goal is to maximize the size of the knowledge space of potential solutions to a problem. Thus, it is the number of relevant comments that is most important, not the total number. While no group is likely to be faced with such a mismatched problem as business students discussing brain surgery, each participant in a meeting naturally has different levels of understanding, interest, and control that influence his or her ability to generate quality ideas. However, no prior research has attempted to model this individual behavior and forecast the number of relevant comments based solely on their feelings about the meeting topic.

\section{EXPERIMENTAL STUDY}

An experiment was conducted using 108 Business students, aged 20 to 46 . The subjects were assigned randomly to 14 groups, each with seven to eight participants because this is the minimum size needed for electronic meeting [4]. Each group was randomly assigned one of five topics to discuss using electronic meeting software implementing the gallery writing technique that allowed each participant to post and view comments anonymously and simultaneously in a face-to-face environment [8].

After 10 minutes exchanging typed comments, group members completed a short questionnaire assessing their opinions about their knowledge, interest, and ability to control the topic using a scale ranging from 1strongly disagree to 7-strongly agree. In addition, objective evaluators determined the number of relevant comments (that is, the comment had something to do with the topic) generated by each participant. Summary results are shown in Table 1.

Table 1: Questionnaire Summary Results

\begin{tabular}{|l|l|l|l|}
\hline Variable & Description & Mean & Std Dev \\
\hline rel & $\begin{array}{l}\text { Number of relevant } \\
\text { comments }\end{array}$ & 6.093 & 3.909 \\
\hline Q1 & $\begin{array}{l}\text { Topic has more than } \\
\text { one solution }\end{array}$ & 5.574 & 1.542 \\
\hline Q2 & $\begin{array}{l}\text { Subject has } \\
\text { knowledge of the } \\
\text { topic }\end{array}$ & $3.685^{*}$ & 1.678 \\
\hline Q3 & Topic is meaningful & 5.204 & 1.898 \\
\hline Q4 & Topic is involving & 5.213 & 1.635 \\
\hline Q5 & Topic is attractive & 4.630 & 1.780 \\
\hline Q6 & Topic is interesting & 5.074 & 1.667 \\
\hline Q7 & Topic is unclear & 2.852 & 1.679 \\
\hline Q8 & $\begin{array}{l}\text { Subject can influence } \\
\text { others about this topic }\end{array}$ & 4.454 & 1.620 \\
\hline Q9 & Topic is difficult & 3.509 & 1.931 \\
\hline
\end{tabular}

* = not significantly different from questionnaire "neutral" value of 4 at $\alpha=0.05$

Table 2 shows that all of the variables were significantly correlated with the number of relevant comments generated by each group member. Therefore, using these variables, it might be possible to accurately forecast the number of comments with a neural network. 
Table 2: Topic Variable Correlations with Relevant Comments

\begin{tabular}{|l|l|c|}
\hline Variable & R & p-value \\
\hline Q1 & 0.377 & $<0.001$ \\
\hline Q2 & 0.393 & $<0.001$ \\
\hline Q3 & 0.247 & 0.010 \\
\hline Q4 & 0.288 & 0.003 \\
\hline Q5 & 0.545 & $<0.001$ \\
\hline Q6 & 0.545 & $<0.001$ \\
\hline Q7 & -0.320 & $<0.001$ \\
\hline Q8 & 0.232 & 0.012 \\
\hline Q9 & -0.369 & $<0.001$ \\
\hline
\end{tabular}

\section{FORECASTING RELEVANT COMMENTS}

We used Neuroforecaster 3.1 with a genetic training algorithm to model the data obtained in the experiment. The first decision to be made was the determination of the in-sample (training) and out-ofsample (testing) data sets. The training set should be large enough for the neural network to adequately train on a large representation of possible inputs, but some data must be left for the testing data set. One tool provided by the software that aids with this subjective decision is the Indicator Distribution Pattern Window [20]. The goal using this tool is to cover as many quadrants as possible in the window, thus exposing the software to many possible problem scenarios. As the training sample size is increased, in general, more quadrants are covered. The nine input variable distribution pattern windows represent a training set size of 88 , leaving 20 observations for testing. We subjectively decided this sample size was large enough.

Another subjective decision is when to stop training. Figure 1 shows the neural network after 1.3 million iterations with the in-sample MAPE reduced to about $19 \%$.

Because the in-sample MAPE was not declining much further at this point, we tested the neural network forecasts with the 20 out-of-sample observations (see Figure 2) and obtained an MAPE of $21 \%$, slightly higher than the in-sample MAPE, which is normal.
Figure 1: Neural Network Training

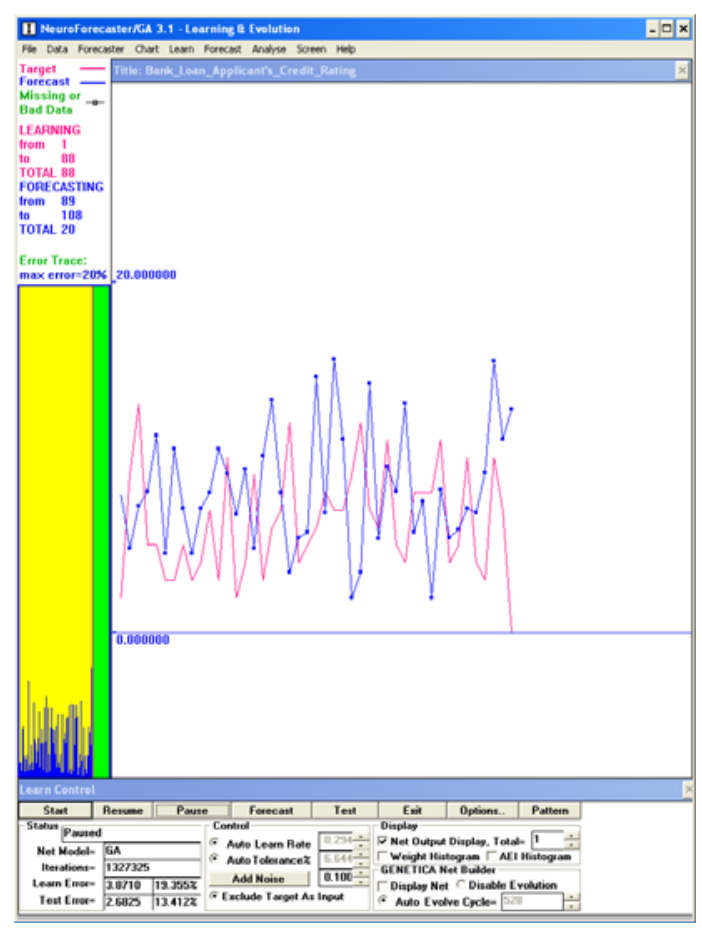

Figure 2: Neural Network Testing

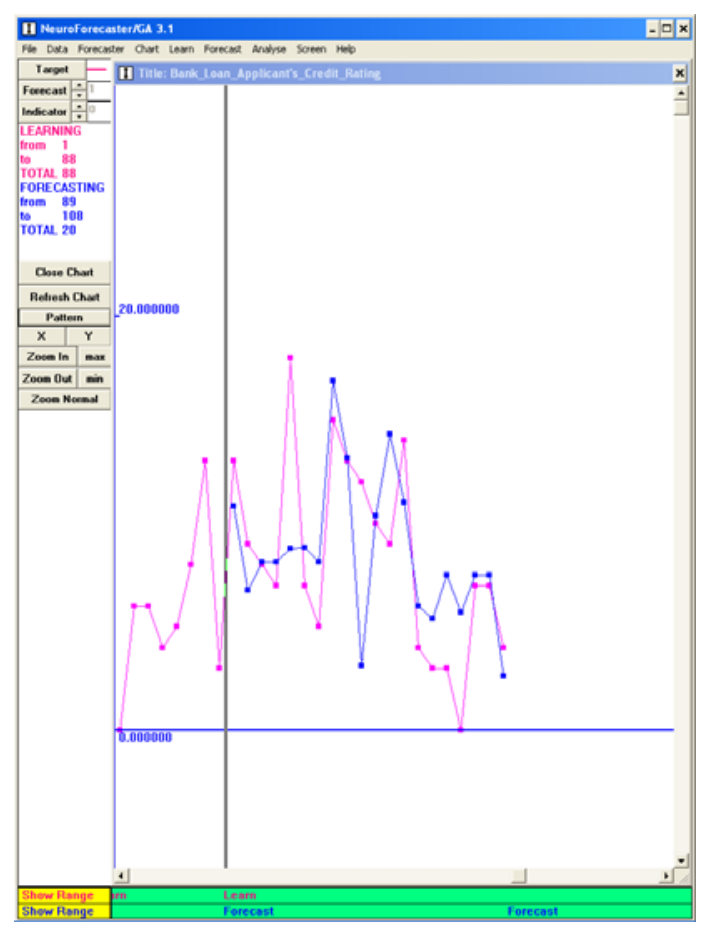


For a comparison, we also conducted a naïve forecast in which the number of relevant comments per individual in the testing set is forecasted to be the same as the average number of relevant comments for all individuals in the training set. This forecast resulted in an MAPE of about $43 \%$. Finally, a multilinear regression forecast was conducted using the SAS General Linear Model (GLM) procedure ( $\mathrm{F}=$ $8.62, \mathrm{p}<0.001)$, resulting in an MAPE of about $31 \%$ for the testing set. Results for all three forecasting techniques are summarized in Table 3.

Table 3: Neural Network, Naïve, and Regression Testing Results

\begin{tabular}{|c|c|c|c|c|c|c|}
\hline 冚 & 文 & 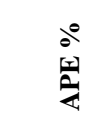 & : & 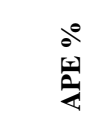 & 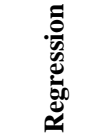 & $\begin{array}{l}\stackrel{\circ}{\circ} \\
\text { 劉 } \\
\frac{2}{2}\end{array}$ \\
\hline 13 & 13.6 & 4.62 & 5.56 & 57.23 & 7.26 & 44.13 \\
\hline 9 & 8.3 & 7.78 & 5.56 & 38.22 & 4.74 & 47.29 \\
\hline 8 & 7.2 & 10.00 & 5.56 & 30.50 & 6.36 & 20.47 \\
\hline 7 & 8.7 & 24.29 & 5.56 & 20.57 & 7.46 & 6.50 \\
\hline 18 & 10.1 & 43.89 & 5.56 & 69.11 & 8.81 & 51.05 \\
\hline 7 & 8.1 & 15.71 & 5.56 & 20.57 & 7.63 & 8.99 \\
\hline 5 & 5.5 & 10.00 & 5.56 & 11.20 & 4.20 & 16.00 \\
\hline 15 & 15 & 0.00 & 5.56 & 62.93 & 5.97 & 60.18 \\
\hline 13 & 12.2 & 6.15 & 5.56 & 57.23 & 6.87 & 47.18 \\
\hline 12 & 3.6 & 70.00 & 5.56 & 53.67 & 6.20 & 48.36 \\
\hline 10 & 8.3 & 17.00 & 5.56 & 44.40 & 7.55 & 24.47 \\
\hline 9 & 14.8 & 64.44 & 5.56 & 38.22 & 4.88 & 45.74 \\
\hline 14 & 11.5 & 17.86 & 5.56 & 60.29 & 9.68 & 30.87 \\
\hline 4 & 4.1 & 2.50 & 5.56 & 39.00 & 5.39 & 34.87 \\
\hline 3 & 3.8 & 26.67 & 5.56 & 85.33 & 3.65 & 21.59 \\
\hline 3 & 4.9 & 63.33 & 5.56 & 85.33 & 3.76 & 25.37 \\
\hline 0 & 5.1 & $0.00 *$ & 5.56 & $0.00 *$ & 2.81 & $0.00 *$ \\
\hline 7 & 7 & 0.00 & 5.56 & 20.57 & 8.78 & 25.45 \\
\hline 7 & 7.5 & 7.14 & 5.56 & 20.57 & 8.55 & 22.08 \\
\hline 4 & 2.7 & 32.50 & 5.56 & 39.00 & 2.80 & 30.00 \\
\hline \multicolumn{7}{|c|}{ Averages } \\
\hline 8.4 & 8.1 & 21.19 & 5.56 & 42.70 & 6.17 & 30.56 \\
\hline
\end{tabular}

* = Absolute Percentage Error (APE) cannot be calculated when the divisor is not positive. Instead, a 0 was substituted as the error for this observation.

A difference of means t-test showed that there was no significant difference between the neural network estimates and the actual numbers of relevant comments per meeting participant $(\mathrm{t}=-0.40$, $\mathrm{p}$ $=0.693$, but there were significant differences between the naïve estimates $(t=-2.72, \mathrm{p}=0.013)$ and the linear regression estimates $(\mathrm{t}=-2.74, \mathrm{p}=0.013)$ and the numbers of relevant comments. Thus, the neural network was more accurate than these two alternative forecasting techniques.

\section{CONCLUSION}

In determining the topic for a discussion, group leaders might want to know before-hand whether or not the problem is appropriate and whether or not the meeting will be a success, as determined, for example, by the number of relevant comments that will ultimately be generated. Using a neural network, a relatively accurate forecast of the numbers of comments generated by each group member can be made based upon the selfassessed interest in and knowledge of the topic and the perceived solution multiplicity and difficulty. Improvements in forecasting accuracy might be obtained using additional variables such as measures of individual typing speed and willingness to contribute to conversations. Future research should investigate the affect of these variables and select a broader range of discussion topics.

\section{REFERENCES}

1. Aiken, M. (1997). Artificial neural systems as a research paradigm for the study of group decision support systems. Group Decision and Negotiation, 6(4), 373-382.

2. Aiken, M. (2002). Topic effects on electronic meeting comments. Academy of Information and Management Sciences, 5(1-2), 115-126.

3. Aiken, M., Garner, B., Paolillo, J., \& Vanjani, M. (1999). A neural network model of group support systems. Proceedings of the 30th Annual Meeting of the Decision Sciences Institute, Nov 20-23, New Orleans, LA.

4. Aiken, M., Krosp, J., Shirani, A., \& Martin, J. (1994). Electronic brainstorming in small and large groups. Information and Management, 27, 141149.

5. Aiken, M. \& Paolillo, J. (2000). An abductive model of group support systems. Information and Management, 37, 87-94.

6. Aiken, M., Sudderth, T., \& Motiwalla, L. (1997). A group support system cost-benefit analysis. International Business Schools Computing Quarterly, 9(1), 1-6.

7. Aiken, M. \& Vanjani, M. (2002). A mathematical foundation for group support system research. Communications of the International Information Management Association, 2(1), 73-83. 
8. Aiken, M. \& Vanjani, M. (1996). Idea generation with electronic poolwriting and gallery writing. International Journal of Information and Management Sciences, 7(2), 1-9.

9. Alonzo, M. \& Aiken, M. (2004). Flaming in electronic communication. Decision Support Systems, 36(3), 205-338.

10. Carmel, E., Herniter, B., \& Nunamaker, J., (1993). Labor-management contract negotiations in an electronic meeting room: A case study. Group Decision and Negotiation, 2, 27-60.

11. Cornelius, C. \& Boos, M. (2003). Enhancing mutual understanding in synchronous computermediated communication by training: Trade-offs in judgmental tasks. Communication Research, 30(2), 147-177.

12. Dennis, A., George, J., Jessup, L., Nunamaker, J., \& Vogel, D. (1988). Information technology to support electronic meetings. MIS Quarterly, 12(4), 591-624.

13. Dennis, A. \& Valacich, J. (1993). Computer brainstorms: More heads are better than one. Journal of Applied Psychology, 78(4), 531-536.

14. Fish, K., Barnes, J., \& Aiken, M. (1995). Artificial neural networks: A new methodology for industrial market segmentation. Industrial Marketing Management, 24(5), 431-438.

15. Gu, L., Aiken, M., \& Wang, J. (2007). Topic effects on process gains and losses in an electronic meeting. Information Resources Management Journal, 20(4), 1-11.

16. Hackman, R. (1968). Effects of task characteristics on group products. Journal of Experimental Social Psychology, 4, 162-187.

17. Huber, G. (1984). Issues in the design of group decision support systems. MIS Quarterly, 8(3), 195-204.
18. Hwang, M. (1998). Did task type matter in the use of decision room GSS? A critical review and a meta-analysis. Omega, 26(1), 1-15.

19. Jessup, L., Connolly, T., \& Galegher, J. (1990). The effects of anonymity on GDSS group process with an idea-generating task. MIS Quarterly, 14(3), 313-321.

20. NIBS (1995). NeuroForecaster 3.1 User Manual, NIBS Pte Ltd, Republic of Singapore.

21. Nunamaker, J., Dennis, A., Valacich, J., Vogel, D., \& George, J. (1991). Electronic meeting systems to support group work. Communications of the ACM, 34(7), 30-39.

22. Nunamaker, J., Vogel, D., \& Konsynski, B. (1989). Interaction of task and technology to support large groups. Decision Support Systems, 5 , 139-152.

23. Pinsonneault, A., Barki, H., Gallupe, R., \& Hoppen, N. (1999). Electronic brainstorming: The illusion of productivity. Information Systems Research, 10(2), 110 - 133.

24. Stefik, M., Foster, G., Bobrow, D., Kahn, K., Lanning, S., \& Suchman, L. (1987). Beyond the chalkboard: Computer support for collaboration and problem solving in meetings. Communications of the ACM, 30(1), 32-47.

25. Valacich, J. \& Dennis, A. (1994). A mathematical model of performance of computer-mediated groups during idea generation. Journal of Management Information Systems, 11(1), 59-72.

26. Vogel, D. \& Nunamaker, J. (1990). Group decision support system impact: A multimethodological exploration. Information and Management, 18, 15-28. 